\title{
MENSAJE DEL DIRECTOR DE LA ESCUELA DE TRABAJO SOCIAL
}

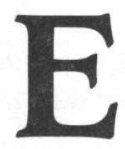

n diciembre de 1967 salió a la luz pública por primera vez

la Revista Humanidad. Hace ya 32 años, este esfuerzo de la Facultad de Trabajo Social de la Escuela Graduada de Trabajo Social Beatriz Lassalle por tener su propia revista se hizo realidad. Su inicio fue enmarcado en la filosofía humanista que emanaba de la Encíclica de Paulo VI, El Desarrollo de los Pueblos (1967). En su primer número se hizo referencia concreta a la cita que colocamos a continuación donde se exponían las aspiraciones de todos los hombres y las mujeres:

Verse libres de la miseria, hallar con más seguridad la propia subsistencia, la salud, una ocupación estable, participar todavía más en las responsabilidades, fuera de toda opresión y al abrigo de situaciones que ofenden su dignidad de hombres; ser más instruidos; en una palabra, hacer, conocer y tener más para ser más; tal es la aspiración de los hombres de hoy, mientras que un gran número de ellos se ven condenados a vivir en condiciones que hacen ilusorio este legítimo deseo. ${ }^{1}$

Recalcaba la doctora Marín (1967), entonces, los objetivos de la revista, que giraban en torno a difundir conocimientos y valores más allá del confín de las aulas universitarias y a generar nuevas inquietudes provocadoras del diálogo tan esencial al quehacer de todo ser humano. Súmesele a estos, que continúan vigentes, la apremiante necesidad de mantener actualizados a los practicantes en Trabajo Social así como a los interesados en esta profesión, con relación a las nuevas tecnologías sociales desarrolladas en el campo de Trabajo

\footnotetext{
${ }^{1}$ El desarrollo de los pueblos (Encíclica de S.S. Pablo VI). Editorial la Milagrosa San Juan, 1967, página 12 .
} 
Social, tanto a nivel teórico como práctico.

Esta revista, que aportó al campo de la Educación en Trabajo Social en Puerto Rico, Estados Unidos, Europa y América Latina, salió de circulación en diciembre de 1978, luego de once años de exitosa publicación. Desde entonces, se han recibido pedidos continuos, reclamando de nuevo su publicación, que se caracterizó por la calidad del material publicado en ella y su pertinencia para practicantes y educadores en Trabajo Social.

La Escuela Graduada de Trabajo Social, en respuesta a este reclamo y reconociendo que se hace imprescindible el recuperar este espacio de divulgación y análisis crítico tan relevante a la clase profesional, se propone publicar una revista que tiene como nombre Análisis e incorpora la experiencia obtenida a través de la Revista Humanidad. Intenta esta publicación convertirse en un nuevo vehículo de análisis crítico de la profesión, su práctica profesional y de la educación en esta disciplina. Interesados en dar continuidad a la tradición comenzada por la Revista Humanidad, hacemos nuestras las palabras de la Dra. Marín (1967):

En resumen, las necesidades humanas básicas son las necesidades físicas con su provisión indispensable de alimentos, abrigo, ropa, salud y seguridad; las necesidades emocionales de amar y ser amado, de estar asociado a sus semejantes para obtener su estímulo y reconocimiento y la necesidad espiritual de lograr la máxima expresión propia para afirmar la naturaleza y relación divina. Ésos son los fundamentos básicos de la existencia humana que han hecho posible el progreso del Hombre y que dan énfasis a los elementos comunes de la humanidad en todas las latitudes del globo terráqueo. No importa dónde viva el hombre, las vidas humanas están todas estrechamente entrelazadas. Las urgencias del Hombre son las mismas bajo circunstancias similares y la suerte de cualquier ser humano nos afecta a todos los demás. Es por esa razón que es menester mostrar una genuina preocupación por nuestros semejantes y contribuir en alguna manera a mejorar su suerte... ${ }^{2}$

\footnotetext{
${ }^{2}$ Ponencia presentada en cinta fono-óptica por la televisora WAPA de San Juan de Puerto Rico, el 4 de mayo de 1967. El programa fue televisado el 28 de mayo de 1967 a las 5:30 p.m. Fue producido por la señora Esther Lowe Gordon como un foro.
} 
Estas palabras representaban, de forma clara, el marco de nuestras necesidades humanas y de las preocupaciones que guiaban nuestra contribución como profesionales. Más allá de ellas, y al acercarnos al inicio de un nuevo milenio lleno de retos y desafíos, la educación en Trabajo Social, apoyada en la experiencia de este Siglo $\mathrm{XX}$ que la vio nacer, debe plantearse nuevos derroteros. Este nuevo contexto de cambios acelerados, de globalización y privatización de servicios, donde el Estado cambia de Estado Benefactor a un Estado Empresarial, requiere reflexión crítica. Análisis, se inserta en este contexto desde donde promoverá la transformación social y el análisis crítico y ponderado de estos cambios que afectan la comunidad puertorriqueña y su entorno. La transformación social, enmarcada en el contexto de la Justicia Social, se presenta como un gran desafío a nosotros como educadores. Sea esta revista entonces un medio a través del cual el análisis crítico, la evaluación de experiencias prácticas y las propuestas alternativas tengan espacio de expresión creadora.

Como todo esfuerzo, éste que da origen a la revista Análisis tuvo como apoyo germinal la Unidad de Investigación Científica de la Escuela, en la figura de la Prof. Cynthia Rodríguez-Parés, su directora, quien, con el apoyo del suscribiente se dio a la tarea de gestarla. Ambos seleccionamos un grupo de trabajadores/as sociales puertorriqueños/as distinguidos/as de capacidad reconocida en el campo de Trabajo Social que irían a componer su Junta Editora. Fue así que surgieron los nombres de Trabajadoras Sociales de la talla de Raquel Seda Rodríguez, Josefa Ramonita Ríos de Caraballo, Magali Ruiz y Trina Rivera de Ríos. Todas ellas reconocidas por su calidad y peritaje en el campo de trabajo social. Posteriormente, este grupo será enriquecido por colegas igualmente reconocidos de América Latina, Estados Unidos y Europa. A todas ellas, nuestra más sincera gratitud por su trabajo y apoyo incondicional.

De la misma manera, la Revista Análisis debe su existencia a su recién nombrada Directora, la Dra. Nilsa $M$. Burgos Ortiz, educadora, investigadora social y escritora reconocida nacional e internacionalmente en el campo de Trabajo Social, quien tendrá a su cargo esta tarea de darle vida a la Revista. Acompaña este esfuerzo la labor realizada por la Sra. Migdalia Alejandro González, Secretaria de la 
Unidad de Investigación y de la Revista Análisis, que se ha caracterizado por ser incansable, dedicada y eficiente en su desempeño. Ha sido su dedicación el pivote de este empeño.

El apoyo del Decanato de Estudios Graduados e Investigación ha sido instrumental en este esfuerzo, pues acreditado en nuestros sueños, apoyaron el proyecto, tanto financiera como académicamente, por lo que le estamos sumamente agradecidos. Su apoyo, al igual que el del Decanato de Asuntos Académicos, representa una ayuda concreta al desempeño de la labor académica de divulgación del conocimiento y hacia la apertura de nuevos horizontes de investigación y publicación en Trabajo Social.

Pretende esta revista también, ser un vehículo donde los futuros profesionales del trabajo social, estudiantes del propuesto programa Doctoral en Trabajo Social, puedan iniciar sus experiencias de publicación en el campo profesional; sobre todo aquellos que se iniciarán en el Programa Doctoral próximo a comenzar. Esperamos que el nuevo milenio nos reciba con este nuevo desafío en la educación en Trabajo Social, marcando horizontes de evolución y crecimiento. Nada más alentador que trabajar hacia la superación humana y profesional. En ese espacio esperamos enmarcarnos.

Víctor I. García Toro 